\title{
MACULA HALO SYNDROME AND NON-PITTING LID OEDEMA IN AN ITALIAN FAMILY
}

\author{
S. PAGLIARINI, S. PUPPARO, M. GHARBIYA, F. REGINE and C. BALACCO GABRIELI \\ Rome, Italy
}

\begin{abstract}
SUMMARY
We report an undocumented association of macula halo syndrome and mechanical ptosis secondary to nonpitting oedema in two members of an Italian family. Macula halo syndrome is universally recognised to be variant of Niemann-Pick disease type $B$, a lipid storage disorder which is ultimately diagnosed by measuring sphingomyelinase activity levels. Although the diagnosis could not be confirmed because of our patients' refusal to undergo enzymatic investigation, the clinical picture proved to be highly compatible with the suggested diagnosis. We discuss the possible clinical differential diagnosis of lipid storage diseases involving the retina.
\end{abstract}

The term 'macula halo syndrome' was first proposed by Cogan in 1983, to describe a peculiar macular abnormality characterised by the presence of bilateral and symmetrical perifoveal rings of fine, whitish, refringent granules. ${ }^{1}$ The characteristic macula halo caused by such granules is associated with NiemannPick type B disease and is considered to be specific for this disorder. ${ }^{2}$ In fact, infrequent case reports on hepato-splenomegaly associated with perifoveal granules, in the absence of signs of retinal malfunction, ${ }^{3}$ were reviewed by Cogan et al. ${ }^{1}$ and re-categorised as Niemann-Pick type B disease. Niemann-Pick disease is a rare autosomal recessive metabolic disorder characterised by impaired activity of the enzyme sphingomyelinase, which leads to intracellular accumulation of sphingomyelin and of phosphosphingolipid cell membranes. Accumulation of these products occurs ubiquitously, although it chiefly affects cells of the reticulo-endothelial system and the organs in which this system is particularly represented. ${ }^{\text {. }}$

Niemann-Pick disease is usually subdivided into four main types. Type $\mathrm{A}$ is the most severe form, with serious involvement of the central nervous

From: Institute of Ophthalmology, II Divisione di Clinica Oculistica, University 'La Sapienza' Rome, Italy.

Correspondence to: Dr S. Pagliarini, II Divisione di Clinica Oculistica, University 'La Sapienza' Rome, Policlinico Umberto I, Viale del Policlinico, I-00161 Rome, Italy. Fax: +39 64457706. system and death by the age of 5 years. A typical cherry red spot is observed at the macula and sphingomyelinase activity is virtually unmeasurable. ${ }^{2}$ Type $\mathrm{B}$ is the mildest form, with onset in late adolescence, marked hepato-splenomegaly, bony alterations and diffuse pulmonary infiltrates. Although the central nervous system is apparently not involved, a macula halo may be present. Some residual sphingomyelinase activity, reduced to levels as low as $10-20 \%$ of normal, is usually found and, as in other types of Niemann-Pick disease, bone marrow biopsy discloses foamy cells. ${ }^{2,4}$ Type C represents the subacute form of Niemann-Pick disease, characterised by onset in the first years of life, after initially normal development, with rapid involvement of the central nervous system and progression to death in a few years. Sphingomyelinase activity is reduced to a variable extent. ${ }^{2}$ Type $\mathrm{D}$ disease is clinically comparable to type $\mathrm{C}$ disease and is also described as the 'Nova Scotia' variant, as it is found in the descendants of a family from that geographic area. In both type $\mathrm{C}$ and type $\mathrm{D}$ disease sphingomyelin accumulation occurs despite normal levels of sphingomyelinase activity ${ }^{2}$ (Table I).

Additionally, types $\mathrm{E}$ and $\mathrm{F}$ have been proposed by Crocker, but the differential criteria for these forms remain unclear. ${ }^{5}$ The clinical variability of the diverse types of Niemann-Pick disease probably resides not only in the amount of residual enzymatic activity, but also in the presence and involvement of different sphingomyelinase iso-enzymes. ${ }^{4,6-8} \mathrm{We}$ present here two members of a southern Italian family affected by macula halo syndrome associated with bilateral chronic non-pitting oedematous swelling of the eyelids - an association previously undocumented.

Case 1

\section{CLINICAL CASES}

The propositus, C.M., a 35-year-old woman and the second of five children whose parents were first 
Table I. Classification of Niemann-Pick disease

\begin{tabular}{|c|c|c|c|c|}
\hline \multirow[b]{2}{*}{ Type } & \multirow[b]{2}{*}{ Age of onset/ethnic background } & \multicolumn{2}{|c|}{ Involvement } & \multirow[b]{2}{*}{ Ocular signs } \\
\hline & & Visceral & Cns & \\
\hline A & Infantile neuronopathic (Ashkenazi Jewish) & ++ & ++ & Cherry-red spot $(50 \%)$ \\
\hline \multirow{2}{*}{$\mathrm{B}$} & Childhood non-neuronopathic (panethnic) & ++ & - & - \\
\hline & Late non-neuronopathic & ++ & - & Macula halo \\
\hline $\mathrm{C}$ & Chronic neuronopathic (panethnic) & $\stackrel{+}{\text { (early jaundice) }}$ & ++ & $\begin{array}{c}\text { Vertical supranuclear palsy, } \\
\text { oculomotor apraxia }\end{array}$ \\
\hline $\mathrm{D}$ & Nova Scotia variant (Acadian) & + & + & - \\
\hline
\end{tabular}

cousins, was referred to us by a dermatologist for questionable bilateral ptosis.

Since the first years of life the patient had had retarded growth but normal psychomotor development. At the age of 5 years hepato-splenomegaly was found. When examined by us the liver was enlarged to two finger widths below the rib margin; the skin had a bronze pigmentation and appeared and felt thickened, particularly on the face. There was a normochromic microcytic anaemia with reticulocytosis and thrombocytopenia. A chest radiograph showed reticular infiltration of the lungs. An iliac crest bone marrow biopsy was performed which showed diffuse foamy cells that stained intensively with luxol fast, sudan black B (lipid stains) and periodic acid-Schiff (PAS). This was classified by the pathologist as being 'blue sea histiocytosis'.

On eye examination a mild mechanical ptosis characterised by drooping of the upper lid to the superior pupillary margin was evident and appeared to be secondary to non-pitting swelling of the eyelids (Fig. 1). Extraocular movements were full. The anterior segment, the lens and the vitreous were normal. There was a ring of perifoveal granular material around both foveae but this was the only fundal abnormality. Visual acuity was 10/10 (6/6) in both eyes and colour vision, ERG, PERG, VEP and fluorescein angiography were normal (Figs. 2, 3).

A provisional diagnosis of Niemann-Pick type B disease was made and investigations of the level of activity of sphingomyelinase and glucocerebrosidase in serum, lymphocytes and skin fibroblasts from a skin biopsy were planned. Unfortunately, the patient refused the enzymatic investigations, although she agreed to bring all her family members to our department for clinical examination. We report below the only other member of the family who had signs of storage disease.

\section{Case 2}

M.P., aged 33 years, sister of M.C. (case 1) was the fourth born of the siblings. She developed anaemia and thrombocytopenia associated with hepato-splenomegaly in the first years of life. She had reduced growth and remained shorter than her four sisters. On examination there was obvious hepatosplenomegaly of about three finger widths below the rib margin. Visual acuity was $10 / 10(6 / 6)$ in both eyes. There was mild degree of bilateral ptosis secondary to non-pitting lid oedema, comparable to that observed in her affected sister. The skin had heavier bronze pigmentation and appeared thicker on the face, and she had full-moon-like facies. The macula haloes were more obvious in this patient (Figs. 4 and 5), and overall she appeared to have more severe skin and hepato-splenic involvement.

\section{DISCUSSION}

The peculiar finding of bilateral annular distribution of granular material around the foveae in our patients, together with hepato-splenomegaly and no evidence of altered retinal function, is similar to what has previously been described as 'macula halo syndrome' and invariably associated with NiemannPick type B disease. ${ }^{1}$

Macula halo syndrome has been reported in seven cases of Niemann-Pick type B disease, three enzymatically proven ${ }^{1,2,4}$ and four prior to enzyme verification described between 1950 and 1970;10-13 its frequency is unknown.

In our patients the diagnosis of Niemann-Pick type $\mathrm{B}$ disease is a presumptive one as it rests on the finding of lipid-rich foamy cells in the bone medullar biopsy, suggestive of a storage disease, and the peculiar clinical picture. Study in the serum, blood leucocytes or cultured skin fibroblasts of the enzymatic activity of sphingomyelinase or other enzymes implicated in lipid storage diseases would have allowed us to make a firm diagnosis, but unfortunately, once the condition was suspected, the patients refused further investigations. The only disorder that would give comparable pathological findings (blue sea histiocytosis with positive staining to luxol fast, sudan black B and PAS) and clinical picture (hepatosplenomegaly, thickened skin with bronze pigmentation, no mental retardation) is Gaucher's disease. ${ }^{9}$ However, none of the various ocular signs that may be found in Gaucher's disease ${ }^{5}$ were seen in our patients, whose eye involvement was represented solely by the 'macula halo.' A particular feature of our patients was the coexistence of mild bilateral mechanical ptosis secondary to non-pitting oedema of the eyelids. Although skin involvement can be found in Niemann-Pick disease, ${ }^{10,11}$ to our knowl- 


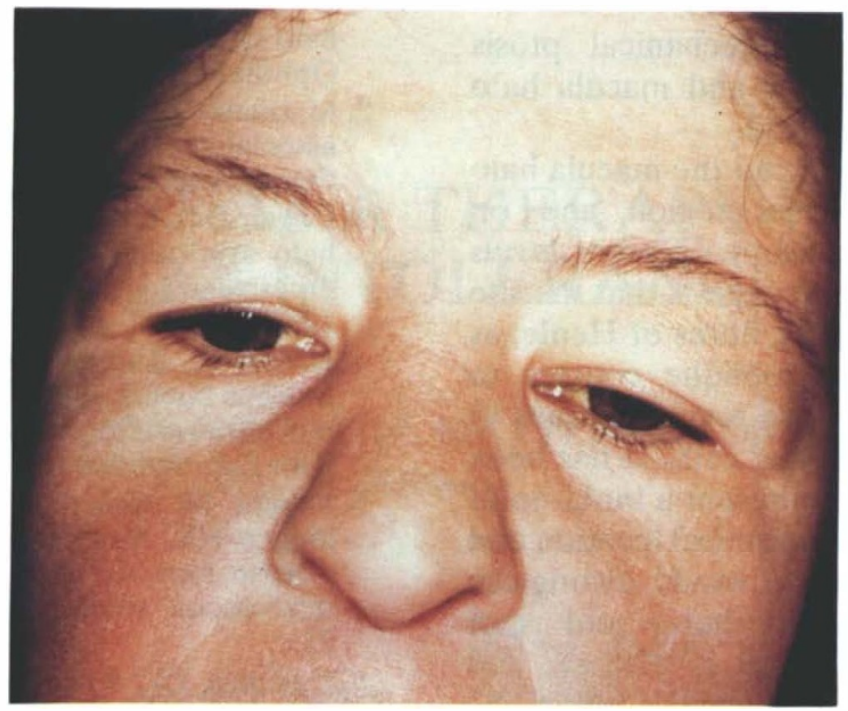

Fig. 1. Case 1. Details of the non-pitting lid oedema.

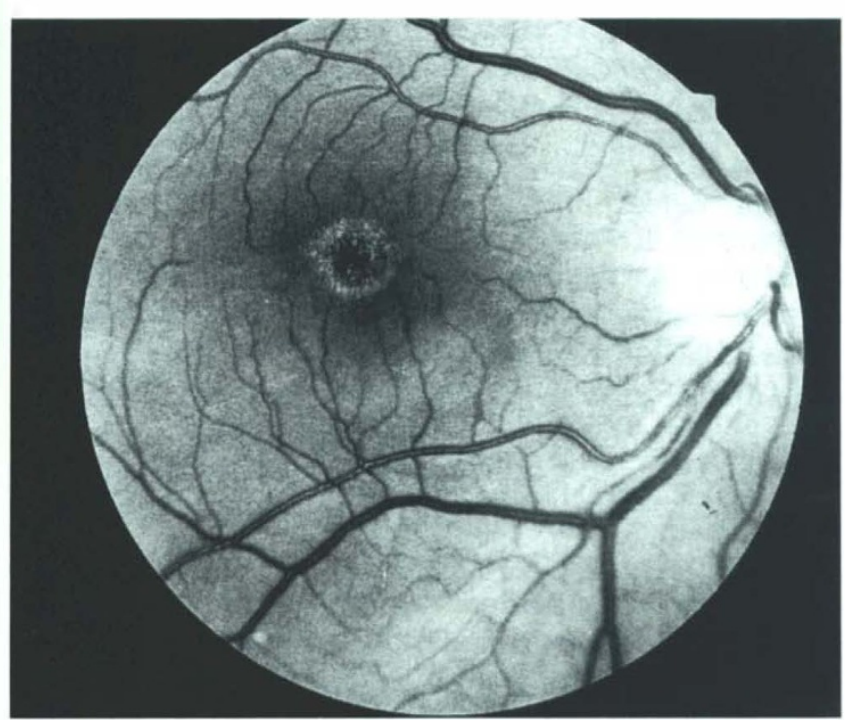

Fig. 2. Case 1. Fundus appearance on red-free photograph of the right eye.

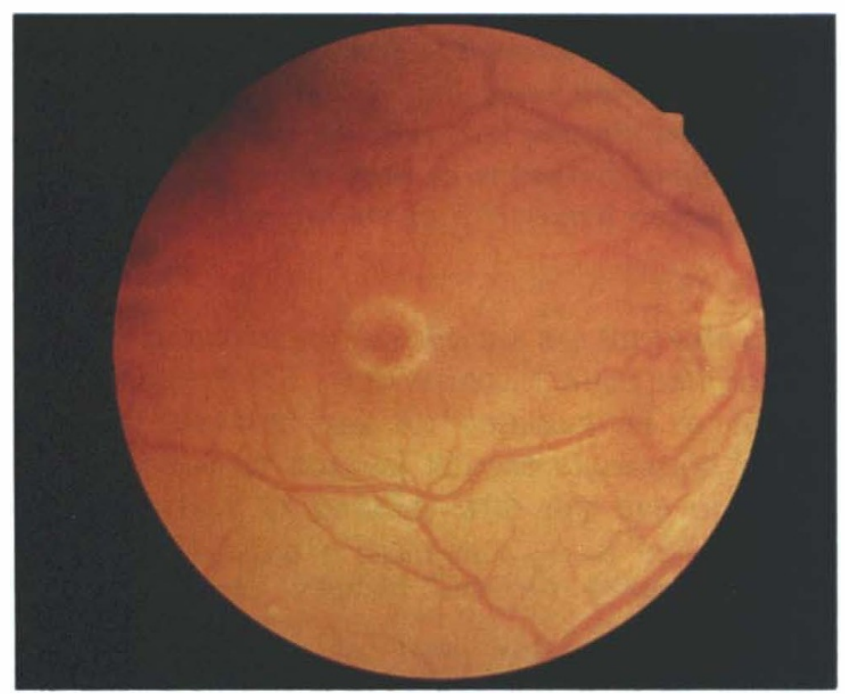

Fig. 4. Case 2. Fundus appearance of the right eye.

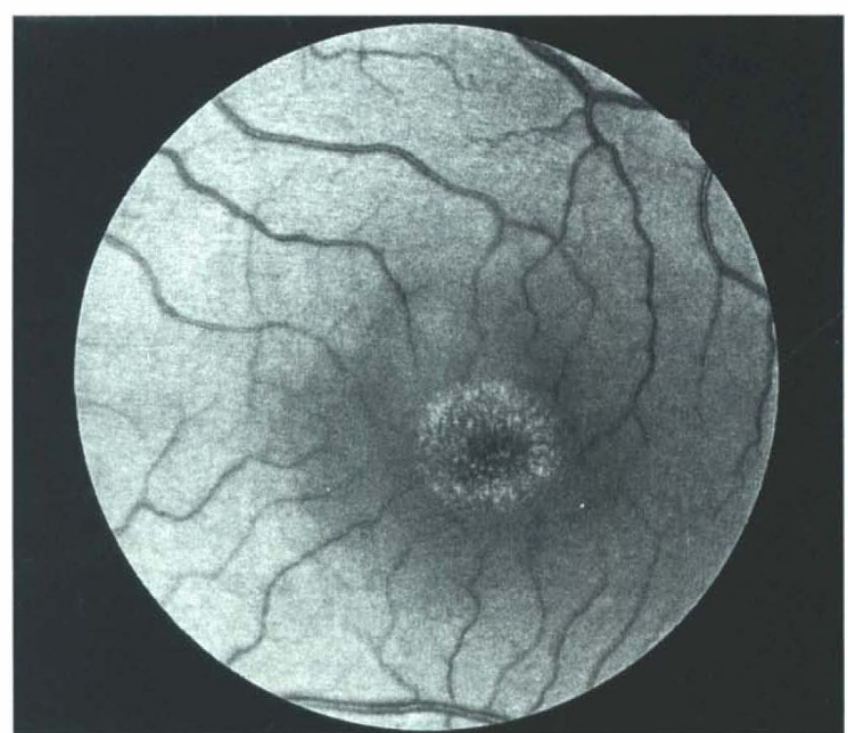

Fig. 3. Case 1. Fundus appearance on red-free photograph of the left eye.

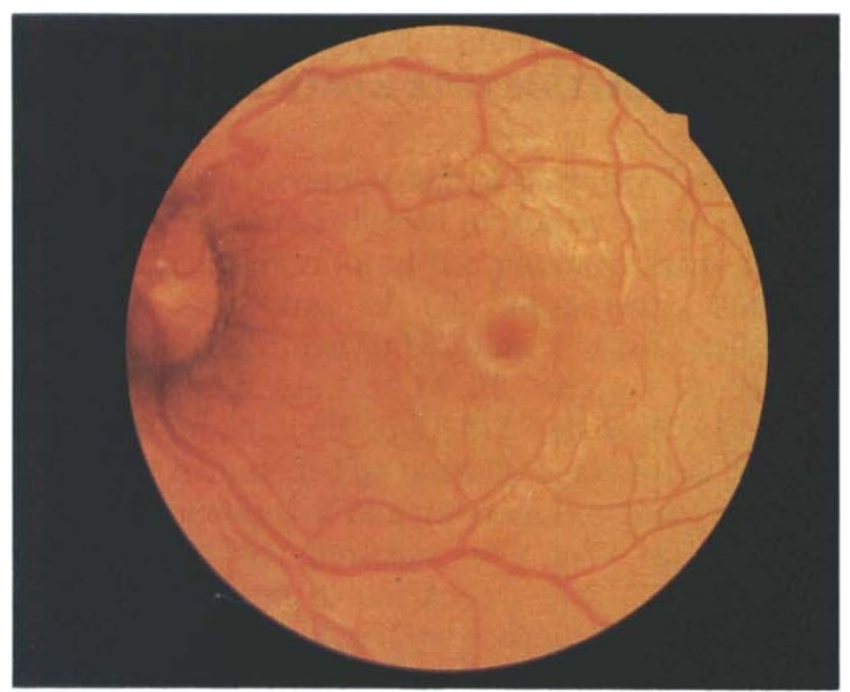

Fig. 5. Case 2. Fundus appearance of the left eye. 
edge an association of mild mechanical ptosis secondary to non-pitting oedema and macula halo syndrome has never been reported.

The granular opacities making up the macula halo were limited to the perifoveal region and on biomicroscopy appeared located at different levels of depth within the retina. This suggests that the site of the granules is the layer of the fibres of Henle, as these fibres run in markedly oblique courses to connect the outer segment of the foveolar cones to the synaptic vesicles of the bipolar cells. It has been proposed that these granules represent a build-up of aberrant carotenoids. ${ }^{1}$ Their anatomical location and appearance, according to Cogan, would distinguish this entity from the classical cherry red spot observable in Niemann-Pick type A disease, and from other storage diseases that chiefly affect the ganglion cells. ${ }^{1}$ However, this is not universally accepted and it has been proposed that the perifoveal granules may accumulate within the retinal ganglion cells. ${ }^{1}$ Because of the lack of pathology, the definitive localisation of the granules and the exact nature of the accumulated material remain unclear. ${ }^{1}$

In conclusion, we present a previously unreported association of macula halo syndrome and bilateral non-pitting oedema of the eyelids. The clinical and histological findings in our patients allow a presumptive diagnosis of Niemann-Pick disease. The predominantly visceral involvement, with sparing of the central nervous system despite the presence of bilateral, symmetrical macula halos, strongly suggests that our patients suffer from the type B disorder.

Key words: Gaucher's disease, Macula halo syndrome, NiemannPick disease, Sphingomyelinase activity, Storage diseases.

\section{REFERENCES}

1. Cogan DG, Chu FC, Barranger JA, Gregg RE. Macula halo syndrome: variant of Niemann-Pick disease. Arch Ophthalmol 1983;101:1698-700.

2. Matthews JD, Weiter JJ, Kolodny EH. Macular halos associated with Niemann-Pick type B disease. Ophthalmology 1986;93:933-7.

3. Cogan DG, Chu FC, Barranger JA, Gregg R. Macula halo syndrome. Read in part before the American Ophthalmological Society, Hot Springs, VA, 25 May, 1982.

4. Harzer K, Ruprecht KW, Seuffer-Shulze D, Jans U. Morbus Niemann-Pick type B: enzymatisch Gesichert mit unerwarteter retinaler Beteiligung. Graefes Arch Klin Exp Ophthalmol 1978;206:79-88.

5. Palmer M, Green WR, Maumenee IH, Valle DL, Singer HS, Morton SJ, Moser HW. Niemann-Pick disease type $\mathrm{C}$; ocular, histopathologic and electron microscopic studies. Arch Ophthalmol 1985;103:81722.

6. Callahan JW, Khalil M. Sphingomyelinosis in human tissues. II. Absence of specific enzyme from liver and brain of Niemann-Pick disease, type C. Pediatr Res 1975;9:908-13.

7. Callahan JW, Khalil M. Sphingomyelinosis in human tissues. III. Expression of Niemann-Pick disease in cultured skin fibroblasts. Pediatr Res 1975;9:914-8.

8. Harzer K, Anzil AP, Schuster I. Resolution of tissue sphingomyelinase isoelectric profile in multiple components is extraction-dependent: evidence for component defect in Niemann-Pick disease type $C$ is spurious. J Neurochem 1977;26:1155-7.

9. Erikson A, Wahlberg I. Gaucher disease - Norrbottnian type: ocular abnormalities. Acta Ophthalmol $1985 ; 63: 221-5$.

10. Sebestyén J, Galfi I. Retinal functions in Niemann-Pick lipidosis. Ophthalmologica 1969;157:349-56.

11. Cogan DG, Federman DD. Retinal involvement with reticuloendotheliosis of unclassified type. Arch Ophthalmol 1964;71:489.

12. Saidi P, Azizi SP, Sarlati R, Sayar N. Rare variant lipid storage disorders. Blood 1970;35:533.

13. Wewalka F. Zur Frage der 'blauen pigmentmakrophagen' im Sternalpunktat. Wien Klin Wochenschr 1950;62: 788-91. 